\title{
Mucuna pruriens as adjunct therapy to levodopa in advanced Parkinson's disease
}

\author{
Fernando Botello-Villagrana and Daniel Martinez-Ramirez* \\ Tecnologico de Monterrey, Escuela de Medicina y Ciencias de la Salud, Monterrey, NL., Mexico
}

\begin{abstract}
Background: Parkinson's disease (PD) is a neurodegenerative disorder whose treatment in advanced stages is often complex and challenging. The treatment goal at this stage is to provide greater clinical stability, with less "off" time and longer "on" time. Mucuna pruriens (MP) is a legume plant traditionally used in Ayurvedic medicine for Parkinsonian-type diseases. This plant contains a diversity of elements, among which levodopa stands out. Objective: We explored the effect of MP as adjunct therapy to levodopa in a PD patient. Methods: We report the case of a 42-year-old woman with PD in advanced stages due to motor fluctuations and dyskinesias. Due to the progression of her disease, the limitations that it generates and the economic inability to opt for other therapies such as surgical treatments, we used MP as an adjunct therapy to levodopa. Results: MP produces a clinical motor effect similar to conventional levodopa. MP shortened the time to reach the "on"state and prolonged this state without exacerbating dyskinesias. Psychiatric side effects were observed only with high dosages of MP. Conclusions: MP shows to be a promising adjunct therapy to levodopa in advanced PD patients without access to other conventional therapies.
\end{abstract}

Key words: Parkinson's disease. Mucuna pruriens. Levodopa. Motor fluctuations. Dyskinesia.

\section{Mucuna pruriens como terapia adjunta a levodopa en enfermedad de Parkinson avanzada}

\section{Resumen}

Antecedentes: La enfermedad de Parkinson (EP) es un trastorno neurodegenerativo cuyo tratamiento en etapas avanzadas suele ser complejo y desafiante. El objetivo del tratamiento en esta etapa es proporcionar una mayor estabilidad clínica, con menos tiempo de "apagado" y más tiempo de "encendido". Mucuna pruriens (MP) es una planta leguminosa utilizada tradicionalmente en la medicina ayurvédica para las enfermedades de tipo parkinsoniano. Esta planta contiene diversidad de elementos, entre los que destaca la levodopa. Objetivo: Exploramos el efecto de la MP como terapia coadjuvante a levodopa en un paciente con EP. Métodos: Presentamos el caso de una mujer de 42 años con EP en estadios avanzados por fluctuaciones motoras y discinesias. Debido a la progresión de su enfermedad, las limitaciones que genera y la imposibilidad económica de optar por otras terapias como los tratamientos quirúrgicos, utilizamos MP como terapia coadyuvante a la levodopa. Resultados: La MP produce un efecto clínico motor similar al de levodopa convencional. MP acortó el tiempo para el estado "on" medicamentoso y lo prolongó este mismo estado sin exacerbar las discinesias. Se observaron efectos secundarios psiquiátricos con dosis altas de MP. Conclusiones: La MP parece ser una terapia coadyuvante prometedora a la levodopa para pacientes con EP avanzada sin acceso a otras terapias convencionales.

Palabras clave: Enfermedad de Parkinson. Mucuna pruriens. Levodopa. Fluctuaciones motoras. Discinesias.

\section{Correspondence:}

*Daniel Martinez-Ramirez

E-mail: daniel.martinez-ramirez@tec.mx
Available online: 01-10-2021 Rev Mex Neuroci. 2021;22(5):180-183 www.revmexneurociencia.com 2604-6180/ C 2021 Academia Mexicana de Neurología A.C. Published by Permanyer. This is an open access article under the CC BY-NC-ND license (http://creativecommons.org/licenses/by-nc-nd/4.0/). 


\section{Introduction}

The management of Parkinson's disease (PD) in advanced stages is complex ${ }^{1}$. During these stages of the disease, PD patients develop variations in the clinical response (e.g., motor and non-motor fluctuations) and/ or involuntary movements induced by the dopaminergic treatment (e.g., dyskinesias) ${ }^{2}$. Treatment in these stages should be focused on providing greater clinical stability during their waking hours, resulting in less "off" time and longer "on" time without generating disabling dyskinesias ${ }^{3}$. At present, different pharmacological strategies in addition to the surgical and device-assisted therapies are recommended to increase the stability of levodopa in the brain ${ }^{4}$. However, these therapies are not fully available in some countries or become economically inaccessible for people affected with PD, thus limiting their treatment options in these advanced stages of the disease.

Mucuna pruriens (MP) is a legume plant belonging to the Fabaceae family that grows widely in tropical and subtropical regions of the world, popularly used in traditional Ayurvedic medicine for Parkinson's-like diseases. MP mainly contains levodopa in addition to other functional components in lesser amounts ${ }^{5}$. Several studies in animals have demonstrated its antioxidant and anti-inflammatory properties suggesting a possible benefit for neurodegenerative diseases such as $\mathrm{PD}^{6}$. In this case report, we describe the clinical response to MP as adjunct therapy to levodopa at different doses, analyzing the following factors: the time to reach the "on" state, the duration of the "on" medication state, the presence and severity of dyskinesias, and presence of adverse effects.

\section{Methods}

This is a 42-year-old woman with a diagnosis of PD subtype postural instability with a 6-year history of gait disorder, Hoehn and Yahr Stage 2 in advanced stages due to fluctuations and dyskinesias. In the initial assessment, the patient presents fluctuations with an "on" state delay of approximately $1-2 \mathrm{~h}$ and an end of the dose deterioration of $1 \mathrm{~h}$, calculating $50 \%$ of the day being in an "off" state, and thus, this condition being disabling for the patient. The duration of the "on" state was $3 \mathrm{~h}$ with non-disabling diphasic dyskinesias, calculating $25 \%$ of the day in this clinical state. In subsequent visits, treatment was optimized by adjusting the dose and frequency of levodopa to $125 \mathrm{mg}$ every $3 \mathrm{~h}$, adding pramipexole as dopamine agonist in dosage of
$3 \mathrm{mg} /$ day divided in three doses, and adding selegiline as monoamine oxidase type B (MAO B) inhibitor at dosages of $10 \mathrm{mg} /$ day. Although proposed, it was not possible for the patient to use a catechol-O-methyl transferase (COMT) inhibitor due to its cost. Due to the clinical progression, advanced therapy options such as surgical or device assisted were considered. However, it is not possible for the patient to consider these options at this moment due to her financial situation. For these reasons and in the presence of disabling fluctuations despite pharmacological optimization, it was decided to start an 8-session trial using MP at different dosages as an adjunct therapy to levodopa in this patient.

\section{Results}

Figure 1 shows the time to reach the "on" state and figure 2 shows the duration of the "on" medication state after trying MP with levodopa at different doses. The results show less time to reach the "on" state and longer duration of the "on" state with the combination of MP and levodopa in comparison to levodopa alone. The presence and severity of dyskinesias did not vary with the different doses tested. Regarding the adverse events of using MP, the patient referred feeling nausea as well as confusion and visual hallucinations. These were observed while the patient was at doses of $20 \mathrm{~g}$ of MP.

\section{Discussion}

In the present case report, we observed the following results: (1) the average time to reach the "on" state was shorter using $20 \mathrm{~g}$ versus $10 \mathrm{~g}$ of MP (39.7 min vs. $47.3 \mathrm{~min})$; (2) the average duration of the clinical "on" state was greater using $20 \mathrm{~g}$ versus $10 \mathrm{~g}$ of MP (241.0 $\mathrm{min}$ vs. $214.3 \mathrm{~min}$ ); (3) the time and severity of dyskinesias were similar between both doses of MP; and (4) gastrointestinal and neuropsychiatric adverse effects occurred only in tests using $20 \mathrm{~g}$ of MP.

At present, there is scarce literature reporting the use of MP in PD. One of the initial reports was an open study of 60 patients with PD evaluating the clinical effect of MP as monotherapy at 12 weeks of follow-up ${ }^{7}$. Doses of $7.5 \mathrm{~g}$ of MP were used per dose, varying from 2 to 5 doses per day depending on the patient's needs. The authors observed a significant improvement in the motor score of the Unified Parkinson's Disease Rating Scale (UPDRS) from 18.2 SD 8.1 to 9.8 SD 7.4 and on the Hoehn and Yahr scale from 2.5 SD 1 to 1.6 SD 1. They 


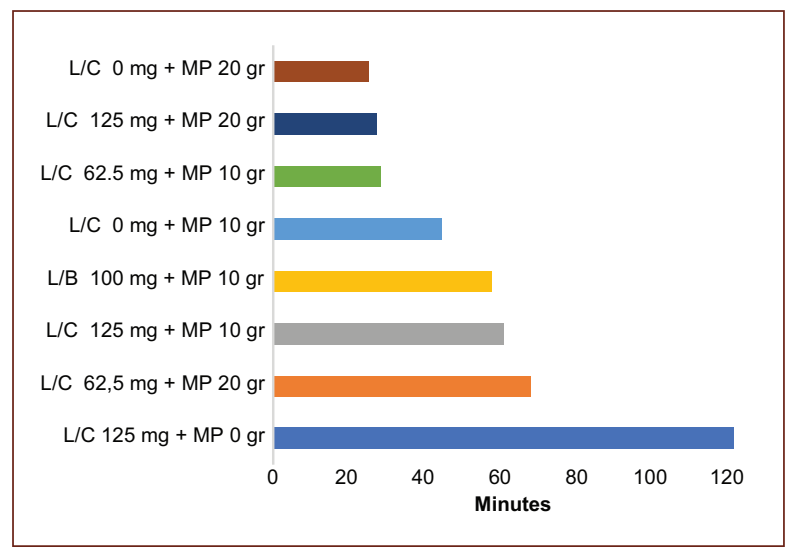

Figure 1. Time to reach the "on" state with different doses of levodopa and Mucuna pruriens. The greatest benefit was observed while using $62.5 \mathrm{mg}$ of levodopa/carbidopa with $10 \mathrm{~g}$ of Mucuna pruriens. Adverse effects such as dizziness, nausea, and neuropsychiatric effects were observed using $20 \mathrm{~g}$ of Mucuna pruriens. The patient did not reach the "on" state at 120 min while using $125 \mathrm{mg}$ of levodopa/carbidopa with $0 \mathrm{~g}$ of Mucuna pruriens so this trial was suspended.

L/C: levodopa/carbidopa; MP: Mucuna pruriens; L/B: levodopa/benserazide.

observed mild gastrointestinal symptoms in $20 \%$ of patients. In another study comprising eight patients with $\mathrm{PD}$, it was observed that $30 \mathrm{~g}$ of MP decreased the time to reach the "on" state and prolonged "on" state time by $21.9 \%$ significantly compared to standard levodopa/carbidopa $^{8}$. They did not observe differences in dyskinesias or tolerability. In a case report, it was shown a reduction in motor and non-motor fluctuations with a sustained response to 3 months of follow-up using levodopa/ benserazide 100/25 mg three tablets daily together with $5 \mathrm{~g}$ of MP in five doses a day with a cup of green tea 9

Another recent study openly investigated 18 patients with PD analyzing motor changes at 90 and $180 \mathrm{~min}$ after administration of the study dose, the duration of the "on" state and adverse effects. The different treatments were used sequentially and randomly, including a dose of dispersible levodopa at a dose of $3.5 \mathrm{mg} / \mathrm{kg}$ combined with levodopa/benserazide at a recommended dose; a pharmaceutical preparation of levodopa without a dopa decarboxylase inhibitor, a placebo dose and two doses of MP, one considered high $(17.5 \mathrm{mg} / \mathrm{kg})$ and the other low $(12.5 \mathrm{mg} / \mathrm{kg})^{10}$. The authors observed that low doses of MP showed a similar motor response to levodopa/benserazide dose with fewer dyskinesias and adverse effects, while the MP at high doses showed a greater motor response, longer duration of "on" state,

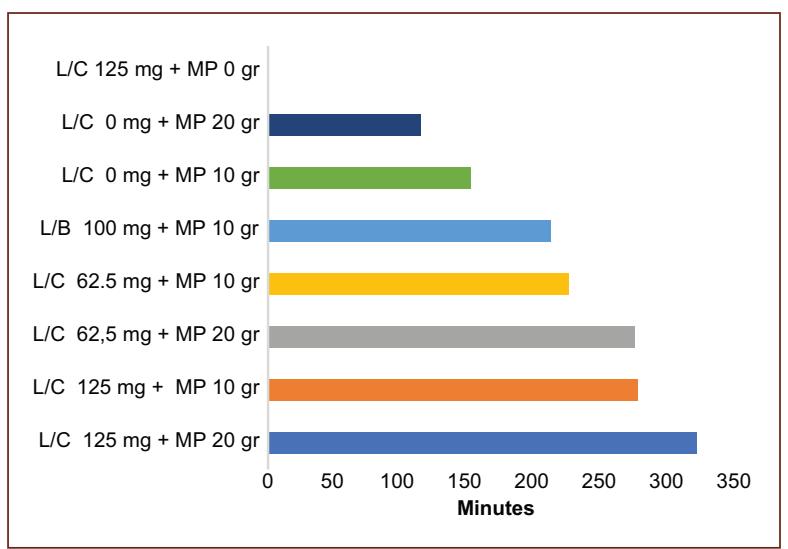

Figure 2. "On" state duration with different doses of levodopa and Mucuna pruriens. The greatest duration of the "on" state can be observed when the patient used the combination of $125 \mathrm{mg}$ of levodopa/carbidopa with $20 \mathrm{~g}$ of Mucuna pruriens, providing an "on" state of $320 \mathrm{~min}$; at $20 \mathrm{~g}$ of Mucuna pruriens, the patient reported nausea and dizziness. Trial with $125 \mathrm{mg}$ of levodopa/carbidopa with $0 \mathrm{~g}$ of Mucuna pruriens was suspended because the patient could not reach the on state.

LC: levodopa/carbidopa; MP: Mucuna pruriens; LB: levodopa/benserazide.

and minor dyskinesias. Fewer adverse effects were also seen with MP compared to levodopa. The most recent study with a 16-week non-inferiority randomized open-label experimental design explored the effect of daily MP consumption versus levodopa/carbidopa in 14 people with PD with motor fluctuations and dyskinesias $^{11}$. A dose of MP was used applying a conversion factor of 3.5-5 times, considering the specific ecotype used of MP whose content is $5.7 \%$ of levodopa. The authors observed a longer duration of the "on" state, no differences were observed in dyskinesias, and there was a similar efficacy in quality of life and in non-motor and motor symptoms. Greater gastrointestinal adverse events were observed with MP.

Our patient had similar therapeutic results as previously described in the literature. Based on the current evidence, although limited, it is suggested that MP provides clinical effects on motor symptoms similar to conventional levodopa, shortening the time to reach the "on" state and prolongs the "on" state without evidence of increasing dyskinesias. Similar clinical effects were observed in our patient, shortening the time to reach "on" state. However, there might be a higher frequency of adverse effects with MP, especially gastrointestinal and neuropsychiatric side effects. 
MP is a seed with a diverse content of elements, including phytates, tannins, saponins, alkaloids, and levodopa. The content of this last element varies with the MP ecotype, with a broad range concentration (from $1.2 \%$ to $9.5 \%$ ), estimating an average of $5.3 \%$; this fact denotes the importance of knowing levodopa's concentration in the MP ecotype that is being used to avoid adverse effects ${ }^{12}$. MP has shown in clinical studies an improvement in Parkinsonian characteristics with a decrease in dyskinesias, as well as a reduction in the time to reach the "on" state and an increase on the "on" state time without presenting serious adverse effects, the most commonly reported being gastrointestinal side effects, especially when consuming a dose $>30 \mathrm{~g}^{7-11}$ This pharmacological profile observed in MP and, specifically, the benefit it provides in relation to control motor fluctuations is possibly due to a better levodopa pharmacokinetic profile attributed to some of the more than 50 constituents identified to date in MP. The mechanisms that allow this have not been established since the analysis of each of the elements that constitute MP, although feasible, is expensive and time consuming. However, genistein or its precursor, genistein contained in the MP seed, has been proposed as elements with a possible dopa decarboxylase inhibitor activity that improves levodopa's pharmacokinetic profile contained in MP ${ }^{13}$.

Some of the limitations of the present work were the inability to determine the percentage of levodopa content in MP used as well as the lack of standardization of the dosages and the bioavailability of MP or any other information regarding its pharmacokinetic profile. However, this therapeutic modality represents an alternative due to its low cost and high availability when compared to standard pharmacological treatment. Furthermore, the use of recommended therapies in these stages of the disease such as deep brain stimulation, due to their high cost, is often not feasible for patients, thus limiting the possibility of adequately controlling the symptoms and, therefore, the quality of life of patients. This opens the opportunity to continue the investigation of MP as a pharmacological therapy in PD in better designed clinical studies allowing the expansion of the scientific knowledge of its use.

\section{Conclusions}

Our observations suggest that MP produces a clinical effect similar to conventional levodopa, shortening the time to reach the "on" state and prolonging the "on" time without exacerbating dyskinesias. Greater gastrointestinal and neuropsychiatric adverse effects are likely to occur with high dosages of MP.

\section{Funding}

This research did not receive any specific grant from funding agencies in the public, commercial, or not-forprofit sectors.

\section{Conflicts of interest}

The authors declare no conflicts of interest.

\section{Ethical disclosures}

Protection of human and animal subjects. The authors declare that the procedures followed were in accordance with the regulations of the relevant clinical research ethics committee and with those of the Code of Ethics of the World Medical Association (Declaration of Helsinki).

Confidentiality of data. The authors declare that they have followed the protocols of their work center on the publication of patient data.

Right to privacy and informed consent. The authors have obtained the written informed consent of the patients or subjects mentioned in the article. The corresponding author is in possession of this document.

\section{References}

1. Armstrong MJ, Okun MS. Diagnosis and treatment of Parkinson disease: a review. JAMA. 2010;323:548-60.

2. Chaudhuri KR, Poewe W, Brooks D. Motor and nonmotor complications of levodopa: phenomenology, risk factors, and imaging features. Mov Disord. 2018;33:909-19.

3. Connolly BS, Lang AE. Pharmacological treatment of Parkinson disease: a review. JAMA. 2014;311:1670-83.

4. Fox SH, Katzenschlager R, Lim SY, Barton B, de Bie RM, Seppi K, et al. International Parkinson and movement disorder society evidence-based medicine review: update on treatments for the motor symptoms of Parkinson's disease. Mov Disord. 2018;33:1248-66.

5. Lampariello LR, Cortelazzo A, Guerranti R, Sticozzi C, Valacchi G. The magic velvet bean of Mucuna pruriens. J Tradit Complement Med. 2012;2:331-9.

6. Pathania R, Chawla P, Khan H, Kaushik R, Khan MA. An assessment of potential nutritive and medicinal properties of Mucuna pruriens: a natural food legume. Biotech. 2010;10:261.

7. Parkinson's Disease Study Group. An alternative medicine treatment for Parkinson's disease: results of a multicenter clinical trial. HP-200 in Parkinson's Disease Study Group. J Altern Complement Med. 1995;1:249-55.

8. Katzenschlager R, Evans A, Manson A, Patsalos PN, Ratnaraj N, Watt H, et al. Mucuna pruriens in Parkinson's disease: a double blind clinical and pharmacological study. J Neurol Neurosurg Psychiatry. 2004;75:1672-7.

9. Gonzalez-Maldonado R, Gonzalez-Redondo R, Di Caudo C. Benefits of the combination of Mucuna, green tea and levodopa/benserazide in Parkinson's disease. Rev Neurol. 2016;62:524-6.

10. Cilia R, Laguna J, Cassani E, Cereda E, Pozzi N, Isaias IU, et al, Mucuna pruriens in Parkinson disease: a double-blind, randomized, controlled, crossover study. Neurology. 2017;89:432-8.

11. Cilia R, Laguna J, Cassani E, Cereda E, Raspini B, Barichella M, et al. Daily intake of Mucuna pruriens in advanced Parkinson's disease: a 16-week, noninferiority, randomized, crossover, pilot study. Parkinsonism Relat Disord. 2019;49:60-6.

12. Cassani E, Cilia R, Laguna J, Barichella M, Contin M, Cereda E, et al. Mucuna pruriens for Parkinson's disease: low-cost preparation method, laboratory measures and pharmacokinetics profile. J Neurol Sci. 2016;365:175-80.

13. Lieu CA, Kunselman AR, Manyam BV, Venkiteswaran K, Subramanian T. A water extract of Mucuna pruriens provides long-term amelioration of Parkinsonism with reduced risk for dyskinesias. Parkinsonism Relat Disord. 2010;16:458-65. 